\section{Synthesis of a Self-Assembled Molecular Capsule that Traps Pyridine Molecules by a Combination of Hydrogen Bonding and Copper(II) Coordination $* *$}

\section{Md. Akhtarul Alam, Munirathinam Nethaji,* and Manabendra Ray*}

Molecule and molecular assemblies with cavities of different size and shape to encapsulate guest molecules have been synthesized in view of their potential use as selective hosts for anion sensing, catalysis, selective recognition, and separation of guest molecules. ${ }^{[1]}$ Rebek, Jr. and co-workers recently

\section{[*] Dr. M. Nethaji}

Department of Inorganic and Physical Chemistry

Indian Institute of Science, Bangalore-560012 (India)

Fax: $(+91) 8023600683$

E-mail: mnetaji@ipc.iisc.ernet.in

Dr. M. Ray, M. A. Alam

Department of Chemistry

Indian Institute of Technology Guwahati (India)

Fax: (+91) 361-2690762

E-mail: manabray@iitg.ernet.in

[***] M.R. thanks Prof. R. N. Mukherjee, IIT Kanpur, Prof. T. N. Guru Row, IISC Bangalore, and CDRI Lucknow, India for providing various instrumental facilities. Financial support from the Council of Scientific and Industrial Research, New Delhi (Grant No. 01/ (1669)/00/EMR-II) for M.R. is gratefully acknowledged.

Supporting information for this article is available on the WWW under http://www.angewandte.org or from the author. demonstrated that the binding of a reagent inside a capsular cavity boosts the rate of a Diels-Alder reaction. ${ }^{[2]}$ The selfassembly of relatively small molecules, through hydrogen bonding, or metal-ligand interactions, proved to be very useful in forming large capsular cavities. ${ }^{[1]}$ While several capsular cavities have been synthesized by using organic frameworks (e.g. resorcinarene, calixarene) ${ }^{[1]}$ coordination complexes with a redox stable metal center, ${ }^{[1]}$ and a few with a redox active metal center, ${ }^{[3]}$ there is no report of a capsular cavity with the redox-active metal center having an available binding site inside the capsule. ${ }^{[4]}$ The synthesis of a capsular cavity with an available coordination site at redox active metal centers inside the pocket can, in principle, facilitate the study of the reactivity of the bound guest molecule inside a cavity. In our effort to synthesize a capsular cavity with a redox center, we have synthesized a self-assembled capsule of an octameric $\mathrm{Cu}^{\mathrm{II}}$ coordination complex by using an easy to synthesize ligand (Scheme 1). This capsule has four guest pyridine molecules trapped inside the cavity (Figure 1), in which two of the pyridine molecules are held with a combination of hydrogen bonds and $\mathrm{Cu}^{\mathrm{II}}$ coordination.

The octameric $\mathrm{Cu}^{\mathrm{II}}$ complex (Figure 1) was synthesized from the tetradentate deprotonated ligand $\left(\mathrm{L}^{2-}\right.$, Scheme 1$)$ and the $\mathrm{Cu}^{\mathrm{II}}$ salt, $\mathrm{Cu}\left(\mathrm{ClO}_{4}\right)_{2} \cdot 6 \mathrm{H}_{2} \mathrm{O}$. Because of the presence of an amine hydrogen atom, an imidazole $\mathrm{N}-\mathrm{H}$ group (a $\mathrm{H}$-bond donor), and carboxylate oxygen atoms (a H-bond acceptor) in

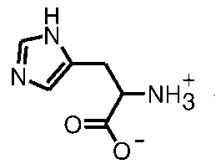<smiles>O=Cc1ccccc1O</smiles>

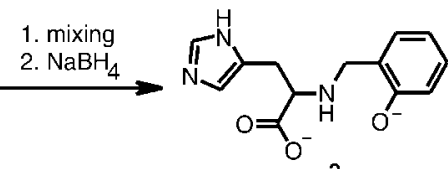

$\mathrm{L}^{2-}$

Scheme 1. Synthesis of the tetradentate ligand, $\mathrm{L}^{2-}$.

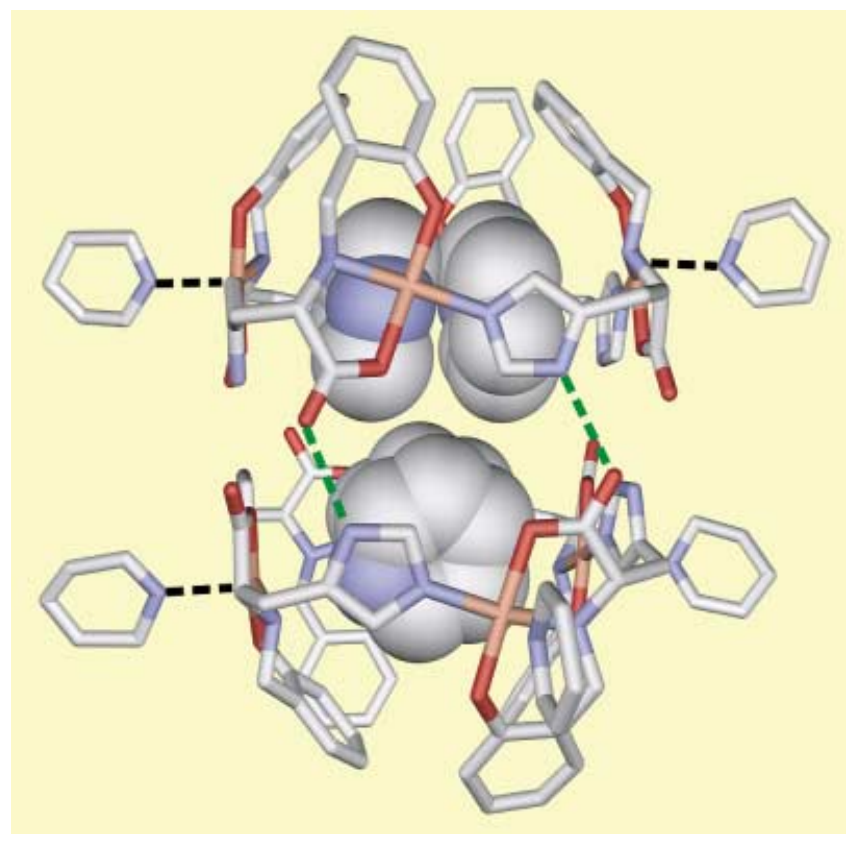

Figure 1. Molecular structure of 1. Solvent molecules are omitted for clarity. 
the ligand, we expected an interligand hydrogen-bonding network to aid in the formation of cages. Crystallization of the complex from pyridine and diethyl ether afforded deep-green crystals of $\left[\mathrm{Cu}_{8} \mathrm{~L}_{8} \mathrm{Py} 10\right] \cdot \mathrm{Py} \cdot 3 \mathrm{MeOH} \cdot\left(\mathrm{C}_{2} \mathrm{H}_{5}\right)_{2} \mathrm{O} \quad(\mathbf{1} ; \mathrm{Py}=$ pyridine). The complex 1 was crystallized in the space group of $P 1$ (No. 1) with two slightly different cup-shaped tetrameric units in the unit cell (1) and $\mathbf{1 b}) \cdot{ }^{[5]}$ The lattice diagram shows that $\mathbf{1 a}$ and $\mathbf{1 b}$ are on top of each other, thus forming a capsule bound through eight hydrogen-bonding interactions between the imidazole $\mathrm{NH}$ groups of one tetramer and nonbonded carboxylate-oxygen atoms of the other tetramer (Figure 1). ${ }^{[6]}$

The structure of $\mathbf{1 a}$ (Figure 2) is a cyclic tetramer with an imidazole "arm" from one monomeric unit coordinated to the next monomeric unit to form a cycle. The coordination geometry around the $\mathrm{Cu}^{\mathrm{II}}$ center is square pyramidal with an $\mathrm{N}_{3} \mathrm{O}_{2}$-donor environment. The four phenolate rings are organized in a manner that effectively closes one side of the square, thus making a cup shaped bottom. Two pyridine molecules are trapped inside $\mathbf{1 a}$ side by side, with each $\mathrm{N}$ atom of the pyridine molecule oriented towards the amine $\mathrm{N}$ atom of the ligand. The $\mathrm{N}$ (trapped pyridine) $-\mathrm{N}$ (amine) separations (N5-N3a $2.990 \AA$, N6-N3c $3.025 \AA$ ) are within the range of $2.68-3.09 \AA$ observed for $\mathrm{N} \cdots \mathrm{HN}$ hydrogen bonds. ${ }^{[7]}$ The space-filling model demonstrates that the two side-by-side pyridine molecules fill the cavity perfectly (Figure 2b).

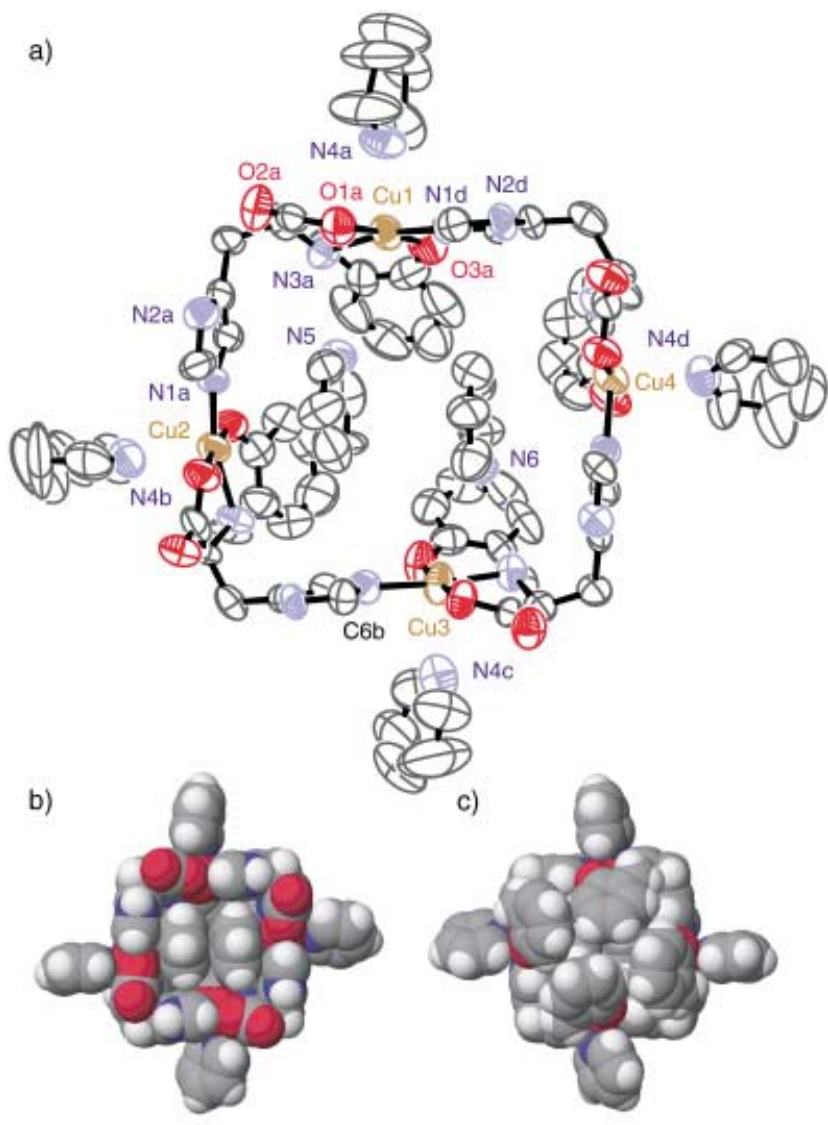

Figure 2. a) One tetrameric copper unit (1 a, $\left[\mathrm{Cu}_{4} \mathrm{~L}_{4} \mathrm{Py}_{6}\right]$ ORTEP diagram, thermal ellipsoids set to $50 \%$ probability). b) Space-filling model of 1 a top view and c) bottom view.
The cyclic tetramer $\mathbf{1 b}$, is similar to $\mathbf{1 a}$ (Figure 3), however, two sides of the cup bend inwardly. The trapped pyridine molecules of $\mathbf{1 b}$ are coordinated to the $\mathrm{Cu}^{\mathrm{II}}$ center instead of being H-bonded to the amine groups (Figure 4). This coordination of the pyridine molecule from inside the

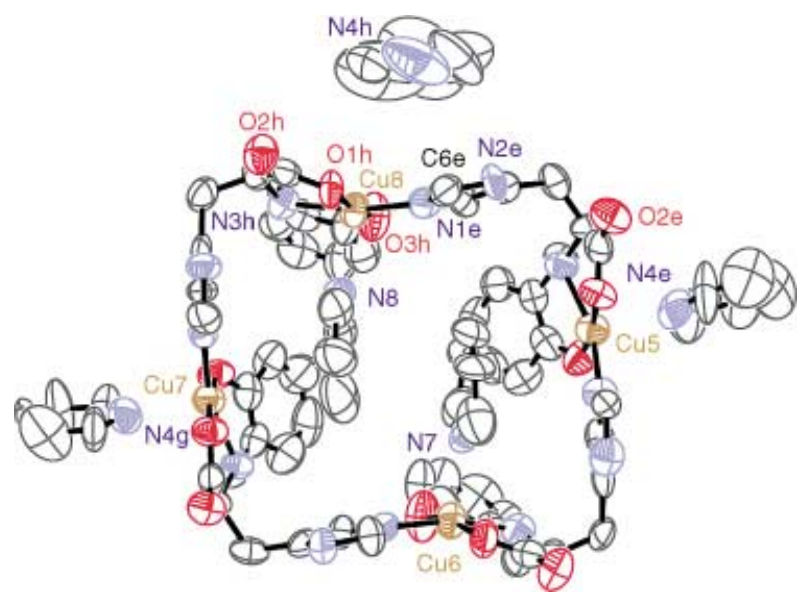

Figure 3. Tetrameric copper unit $\left(\mathbf{1} \mathbf{b},\left[\mathrm{Cu}_{4} \mathrm{~L}_{4} \mathrm{Py}_{4}\right] \mathrm{Py}\right.$, ORTEP diagram, thermal ellipsoids set to $50 \%$ probability).
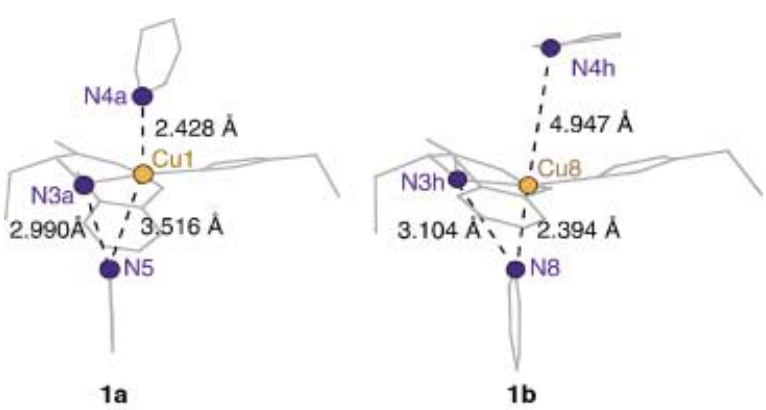

Figure 4. Part of the $\mathrm{Cu}_{4} \mathrm{~L}_{4}$ unit of $\mathbf{1} \mathbf{a}$ and $\mathbf{1} \mathbf{b}$ showing the change in bonding interactions between trapped pyridine molecules, amine $\mathrm{N}$ atoms, $\mathrm{Cu}^{\prime \prime}$ centers, and external pyridine molecules.

cavity to the $\mathrm{Cu}^{\mathrm{II}}$ center results in the deviation of the $\mathrm{Cu} 8$ and $\mathrm{Cu} 6$ atoms from the plane described by O1, N3, O3, N1 towards the trapped pyridine (shift of 0.194 and $0.203 \AA$ for $\mathrm{Cu} 8$ and $\mathrm{Cu} 6$, respectively). Consequently, there is no coordination of the external pyridine molecules to the $\mathrm{Cu} 8$ and $\mathrm{Cu} 6$ atoms, as square-pyramidal geometry is preferred for $\mathrm{Cu}^{\mathrm{II}}$ complexes over octahedral geometry because of JahnTeller distortions. Thus, the coordination sites at the copper centers are accessible from inside the cyclic tetramer.

The two halves of the capsule exhibit contrasting binding with guest molecules. In $\mathbf{1 a}$, the $\mathrm{Cu} 1$ and $\mathrm{Cu} 3$ atoms are each coordinated by an external pyridine molecule, but not by the trapped pyridine molecules. On the other hand, in $\mathbf{1 b}$ the $\mathrm{N}$ atom of the pyridine molecule (N8) is coordinated to $\mathrm{Cu} 8$ (similarly $\mathrm{N} 7$ to $\mathrm{Cu} 6$ ). The N8-N3h(amine) separation of $3.104 \AA$ in $\mathbf{1 b}$ is closer to $\mathrm{N}$...HN hydrogen bonding range of 2.68-3.09 $\AA$ (Figure 4). ${ }^{[7]}$ Thus, the presence of a N-H close to the $\mathrm{Cu}^{\mathrm{II}}$ center allow trapped pyridine molecules in $\mathbf{1} \mathbf{b}$ to bind using both metal-ligand interactions and hydrogen bonding, 
simultaneously. This factor makes the trapped pyridine molecules less labile compared to the external pyridine molecules as observed in the solution studies (see below). We are not aware of this type of binding in any other reported capsular cavity.

The $\mathrm{Cu}-\mathrm{N}$ (external pyridine) distances in molecules $\mathbf{1 a}$ and $1 \mathbf{b}(2.4-2.5 \AA$, see Supporting Information) are considerably longer than $\mathrm{Cu}-\mathrm{N}$ (apical pyridine) bond length of $2.17 \AA$ in $[\mathrm{Cu}$ (Cyclops) $\mathrm{Py}] \mathrm{ClO}_{4}{ }^{[8]}$ (Cyclops = difluoro-3,3' (trimethylenedinitrilo)bis(2-butanoneoximato)borate) and 2.12, $2.13 \AA$ in $\mathrm{Cu}_{2}(\mathrm{OAc})_{4} \mathrm{Py}_{2},{ }^{[9]}$ but within the range of 2.6-2.8 $\AA$ for apical $\mathrm{Cu}-\mathrm{N}^{[10]}$ bond lengths. This makes the externally bound pyridine molecules particularly labile.

The crystals desolvate rapidly and loose crystallinity on isolation. The elemental analysis matches with the formula $\left[\mathrm{Cu}_{8} \mathrm{~L}_{8} \mathrm{Py}_{4}\left(\mathrm{H}_{2} \mathrm{O}\right)_{8}\right]$. Thermogravimetric analysis (TGA) exhibits a curve that corresponds to a weight loss of $5.3 \%$ in the 30 $110^{\circ} \mathrm{C}$ range and a further $11.4 \%$ loss in the $180-230^{\circ} \mathrm{C}$ temperature range, which corresponds to the removal of eight water and four pyridine molecules (expected total of $15.1 \%$ ). We believe that these pyridine molecules are those that were trapped inside the cavity. The room temperature magnetic moment is less than that expected for a $S=1 / 2$ system, which indicates the possible presence of antiferromagnetic coupling between the $\mathrm{Cu}^{\mathrm{II}}$ centers.

The electrospray ionization mass spectra of $\mathbf{1}$ in $\mathrm{MeOH}$ shows the presence of a $\mathrm{Cu}_{4} \mathrm{~L}_{4}$ unit, but no peak was observed corresponding to the pyridine adduct. This is not surprising as the hydrogen-bonding network holding the two halves of the capsule open up in a protic solvent such as $\mathrm{MeOH}$, and the trapped pyridine molecules axially coordinated to the kinetically labile $\mathrm{Cu}^{\mathrm{II}}$ center are replaced by solvent molecules. Thus, the $\mathrm{Cu}_{4} \mathrm{~L}_{4}$ units are stable in $\mathrm{MeOH}$. The EPR spectrum of $\mathbf{1}$ in $\mathrm{MeOH}$ at $77 \mathrm{~K}$ is typical for a distorted square pyramidal geometry around a $\mathrm{Cu}^{\mathrm{II}}$ center. ${ }^{[11]}$

In conclusion, we have synthesized a new self-assembled capsule by using an easy to synthesize ligand, and a $\mathrm{Cu}^{\mathrm{II}}$ salt. The capsule has enough space inside to accommodate four pyridine molecules. The capsule has both $\mathrm{H}$-bonds and kinetically labile $\mathrm{Cu}^{\mathrm{II}}$ centers which are available for binding from inside the cavity. Thus, we have observed a novel guest binding inside the cavity that uses both hydrogen bonds and metal coordination at the same time.

\section{Experimental Section}

Elemental analysis calcd (\%) for $\mathbf{1} \quad \mathrm{Cu}_{8}\left(\mathrm{C}_{13} \mathrm{H}_{13^{-}}\right.$ $\left.\mathrm{N}_{3} \mathrm{O}_{3}\right)_{8} \cdot\left(\mathrm{C}_{5} \mathrm{H}_{5} \mathrm{~N}\right)_{4} \cdot 8 \mathrm{H}_{2} \mathrm{O}: \mathrm{C} 48.94, \mathrm{H} 4.64, \mathrm{~N} 12.88$; found: $\mathrm{C} 48.68, \mathrm{H}$ $4.51, \mathrm{~N}$ 12.92. IR $(\mathrm{KBr}, \tilde{v}): 1615(\mathrm{sh}), 1596(\mathrm{~s}) \mathrm{cm}^{-1} \tilde{v}(\mathrm{COO})_{\text {asym }}$; $1388(\mathrm{~s}) \mathrm{cm}^{-1} \tilde{v}(\mathrm{COO})_{\mathrm{sym}} \cdot \Lambda_{\mathrm{M}}:(\mathrm{MeOH}) 2 \mathrm{~S} \mathrm{~cm}^{-2} \mathrm{~mol}^{-1}$. ESI-MS(+) in $\mathrm{MeOH}$ for $\left\{\left[\mathrm{Cu}_{4}(\mathrm{~L})_{4}\right]+\mathrm{H}\right\}^{+}, m / z$ calculated 1291.1 , found $1290.8 ; \mathrm{UV} /$ Vis: $\lambda_{\max }[\mathrm{nm}]\left(\varepsilon\left[\mathrm{M}^{-1} \mathrm{~cm}^{-1}\right) / \mathrm{Cu}\right.$ : in pyridine:, $416(520), 668(170)$; in MeOH: 273 (5700), 382 (920), 686 (150). EPR: powder; $300 \mathrm{~K} 2.116$ (isotropic), $77 \mathrm{~K}, 2.118$ (isotropic); $\mathrm{MeOH}, 77 \mathrm{~K}, g_{\|}=2.253, g_{\perp}=$ 2.060, $\mathrm{A}_{\|}=175 \mathrm{G}$. $\mu_{\text {eff }}$ (powder, $\left.298 \mathrm{~K}\right) ; 1.63 \mu_{\mathrm{B}} / \mathrm{Cu}$.

Keywords: amino acids - cavitand - copper · hydrogen bonds . self-assembly
[1] Selected review articles on supramolecular cages and capsules; a) P. J. Stang, B. Olenyuk, Acc. Chem. Res. 1997, 30, 502; b) J. Rebek, Jr., Acc. Chem. Res. 1999, 32, 278; c) A. Jasat, J. C. Sherman, Chem. Rev. 1999, 99, 931; d) S. R. Seidel, P. J. Stang, Acc. Chem. Res. 2002, 35, 972; e) F. Hof, S. L. Craig, C. Nuckolls, J. Rebek, Jr., Angew. Chem. 2002, 114, 1556; Angew. Chem. Int. Ed. 2002, 41, 1489; f) M. Fujita, Chem. Soc. Rev. 1998, 27, 417; g) M. Fujita, K. Umemoto, M. Yoshizawa, N. Fujita, T. Kusukawa, K. Biradha, Chem. Commun. 2001, 509.

[2] a) J. Kang, G. Hilmersson, J. Santamaria, J. Rebek, Jr., J. Am. Chem. Soc. 1998, 120, 3650; b) J. Kang, J. Santamaria, G. Hilmersson, J. Rebek, Jr., J. Am. Chem. Soc. 1998, 120, 7389.

[3] a) O. D. Fox, N. K. Dalley, R. G. Harrison, J. Am. Chem. Soc. 1998, 120, 7111; b) O. D. Fox, N. K. Dalley, R. G. Harrison, Inorg. Chem. 1999, 38, 5860; c) O. D. Fox, N. K. Dalley, R. G. Harrison, Inorg. Chem. 2000, 39, 620; d) O. D. Fox, J. F. Y. Leung, J. M. Hunter, N. K. Dalley, R. G. Harrison, Inorg. Chem. 2000, 39, 783.

[4] There are few macrocyclic coordination complexes with available metal coordination sites inside the macrocycle. $\mathrm{Cu}^{\mathrm{II}} ; \mathrm{A}$. W. Maverick, F. E. Klavetter, Inorg. Chem. 1984, 23, 4129. Co ${ }^{\mathrm{II}}$; A. W. Schwabacher, J. Lee, H. Lei, J. Am. Chem. Soc. 1992, 114, 7597. With redox inactive $\mathrm{Zn}^{\mathrm{II}}$, review; "Templating, Selfassembly, and Self-organization": M. Fujita in Comprehensive Supramolecular Chemistry, Vol. 9 (Eds.: J.-P. Sauvage, M. W. Hosseini), Pergamon, Oxford, 1996, chap. 7.

[5] The crystal was mounted with mother liquor inside the capillary for data collection. Crystal structure analysis of $\mathbf{1}$ : $\mathrm{C}_{166} \mathrm{H}_{181} \mathrm{Cu}_{8} \mathrm{~N}_{35} \mathrm{O}_{28}, M_{\mathrm{r}}=3622.8$, deep-green crystal $0.3 \times 0.3 \times$ $0.2 \mathrm{~mm}^{3}$, triclinic $P 1$ (No. 1), $a=16.845(4), b=18.268(4), c=$ 20.167(4) $\AA ; \alpha=92.507(4), \beta=112.207(4), \gamma=105.636(4)^{\circ} ; V=$ $5459(2) \AA^{3}, Z=1, \rho_{\text {calcd }}=1.102 \mathrm{Mg} \mathrm{m}^{-3}, \mathrm{Mo}_{\mathrm{K} a}$ radiation , $\lambda=$ $0.71073 \AA$, measured reflections 60205 , unique reflections 44425, temperature 293(2) K. Data were collected on a Bruker Smart CCD Area Detector system with graphite monochromator. The structure was solved by direct methods and refined on $F^{2}$ by full-matrix-block least squares (G. M. Sheldrick, SHELXL97, University of Göttingen, Göttingen (Germany), 1997). In refinement, data/restraints/parameters are $44425 / 3 / 2046$. The final $R 1=0.0868, w R 2=0.2164(I>2 \sigma(I)) ; R 1=0.2725, w R 2=$ 0.2890 (all data), GOF on $F^{2}=0.730$. CCDC- 197602 contains the supplementary crystallographic data for this paper. These data can be obtained free of charge via www.ccdc.cam.ac.uk/conts/ retrieving.html (or from the Cambridge Crystallographic Data Centre, 12 Union Road, Cambridge CB21EZ, UK; fax: (+ 44)1223-336-033; or deposit@ccdc.cam.ac.uk).

[6] The (imidazole) $\mathrm{N}-\mathrm{H} \cdots \mathrm{O}$ (carboxylate) separations in $\mathbf{1}$ are between 2.69 and $2.78 \AA$ A. Reported range 2.69-2.98 ̊; a) S. M. Couchman, J. C. Jeffery, M. D. Ward, Polyhedron 1999, 18, 2633; b) K. Sakai, K. Matsumoto, J. Am. Chem. Soc. 1989, 111, 3074.

[7] a) M. B. Ferrari, G. G. Fava, M. Lanfranchi, C. Pelizzi, P. Tarasconi, J. Chem. Soc. Dalton Trans. 1991, 1951; b) R. Anulewicz, I. Wawer, T. M. Krygowski, F. Männle, H. Limbach, J. Am. Chem. Soc. 1997, 119, 12223.

[8] O. P. Anderson, A. B. Packard, Inorg. Chem. 1980, 19, 2123.

[9] G. A. Barclay, C. H. L. Kennard, J. Chem. Soc. 1961, 5244.

[10] "Tables of Interatomic Distances and Configuration in Molecules and Ions," Chem. Soc. Special Publ. No.11.

[11] U. Sakaguchi, A. W. Addison, J. Chem. Soc. Dalton Trans. 1979, 600 . 